\title{
Positive and Negative Perfectionism Scale
}

National Cancer Institute

\section{Source}

National Cancer Institute. Positive and Negative Perfectionism Scale. NCI Thesaurus.

Code C123143.

A 40-item self-report inventory designed to assess levels of positive and negative perfectionism, and distinguish between "normal" and "neurotic" perfectionism.

Participants use a 5-point Likert scale that ranges from strongly disagree to strongly agree. 